\title{
NPC-11 Phase III Trial Concerning Apnea of Prematurity in Japanese Neonates: A Study of Safety, Efficacy and Pharmacokinetics
}

Masatoshi Kondo ${ }^{1 *}$, Hiroyuki Kitajima ${ }^{2}$, Toshio Yamazaki ${ }^{3}$, Mitsuo Ohzeki ${ }^{4}$ and Susumu Itoh ${ }^{5}$

${ }^{1}$ Department of Neonatology, Tokyo Metropolitan Children's Medical Center, Tokyo, Japan.

${ }^{2}$ Department of Neonatal Medicine, Osaka Medical Center and Research Institute for Maternal and Child Health, Osaka, Japan

${ }^{3}$ Department of Pediatrics, Fujita Health University School of Medicine, Aichi, Japan

${ }^{4}$ Nobelpharma Co., Ltd, Tokyo, Japan

${ }^{5}$ Department of Pediatrics, Facility of Medicine, Kagawa University, Kagawa, Japan

\begin{abstract}
Objective: To study the safety, efficacy, and pharmacokinetics of caffeine citrate in the treatment of apnea of prematurity in Japanese neonates.

Study design: A non-blind, uncontrolled, multicenter, collaborative clinical trial.

Setting: Three neonatal intensive care units in Japan

Patient inclusion criteria: Neonates at the post conceptional age of 28 weeks to 33 weeks who were diagnosed with apnea of prematurity.

Main outcome measures: $50 \%$ or greater reduction in apneic episodes, adverse effects, and pharmacokinetics.

Method: Day 1 - Intravenous (IV) administration of caffeine citrate loading dose of $20 \mathrm{mg} / \mathrm{kg}$, administered over 30 minutes. From day 2 onward - Commencement of administration of maintenance dose (caffeine citrate dose of $5 \mathrm{mg} / \mathrm{kg}$ ) once daily intravenously over 10 minutes or orally. In the case that event incidence was reduced, the maintenance dose continued to be administered until day 10. If the doctor judged the initial maintenance dose to be ineffective, or its efficacy to be insufficient, the maintenance dose was raised to $10 \mathrm{mg} / \mathrm{kg} / \mathrm{day}$.

Results: 23 patients fitting the specifications were found, and dosing was commenced. The reduction rate in apneic episodes during the trial was from $43.5 \%$ to $60.9 \%$. Severe adverse effects were not noted. Mean serum concentration was maintained within the therapeutic range, between 11.87 and $18.82 \mathrm{mg} / \mathrm{L}$. Data from clinical trials (Study OPR-001) in the United States, which were similar in methodology to this trial, were used when analyzing population pharmacokinetics. No difference due to race

Conclusion: Caffeine citrate dosing for treatment of apnea of prematurity was effective, produced no safety problems and showed good tolerability. Additionally, no differences between Japanese and Americans with regard to efficacy, safety and
\end{abstract} pharmacokinetics were observed

Identifier of this clinical trial: NCT01408173

Keywords: Caffeine citrate; Apnea of prematurity; Japanese neonates; population pharmacokinetics; Adverse effect

\section{Introduction}

An episode of apnea of prematurity is generally defined [1-3] as cessation of breathing for 20 seconds or more or cessation of breathing accompanied by bradycardia or cyanosis. Among preterm neonates at the gestational age of 36 weeks or less, it is one of the most frequently encountered medical conditions [4]. Thought to be due to incomplete development of the brainstem, the onset frequency is inversely proportional to birth weight. Apnea of prematurity occurs in $25 \%$ of low birth weight infants and in up to $84 \%$ of very low birth weight infants $[5,6]$.

Treatment consists first of removing causative factors by controlling body temperature, administering low concentrations of oxygen, or applying physical manipulation. When these treatments were insufficient to the control apnea of prematurity, management of breathing, by administering xanthine type drugs, using mechanical ventilation, nasal CPAP, or nasal DPAP, was carried out. Because there were concerns about artificial respiration devices giving rise to complications such as chronic lung disease (bronchopulmonary dysplasia(BPD)), infection due to long-term intubation, pharynx/ trachea stenosis, etc., which constitute significant prognostic factors, carrying out drug treatments before having recourse to ventilation therapy is widespread [6]. In terms of pharmacotherapy, xanthine type drugs (aminophylline, theophylline, caffeine etc.) are the first choice in the treatment of apnea of prematurity both in Japan and overseas.
Caffeine citrate compares with aminophylline and theophylline in the following ways [7-9]: (1) The therapeutic index for caffeine citrate is wide, so the danger of adverse reactions is low; (2) the necessity for therapeutic drug monitoring is low; (3) the efficacy and safety of longterm administration has been proven; (4) because absorption is fast and complete when orally administered, the transition from intravenous to oral administration is easy, and adjustments in dosing at the time of transition are unnecessary; (5) because the serum elimination half-life is long, it is possible to maintain efficacy with a single daily dose. Recently, some authors reported that early caffeine therapy had improved neonatal outcome (death, BPD, retinopathy of prematurity et al). A change in practice toward earlier initiation of caffeine therapy is already occurring [10-12].

*Corresponding author: Masatoshi Kondo, Department of Neonatology, Tokyo Metropolitan Children's Medical Center, 2-8-29 Musashidai, Fuchu-shi, Tokyo 183 0861, Japan, Tel: +81-426-300-5111; Fax: +81-426-362-8162; E-mail: masatoshi kondou@tmhp.jp

Received Decembeer 24, 2015; Accepted January 13, 2016; Published January 16,2016

Citation: Kondo M (2016) NPC-11 Phase III Trial Concerning Apnea of Prematurity in Japanese Neonates: A Study of Safety, Efficacy and Pharmacokinetics. Pharm Anal Acta 8: 458. doi:10.4172/2153-2435.1000458

Copyright: (C) 2016 Kondo M. This is an open-access article distributed under the terms of the Creative Commons Attribution License, which permits unrestricted use, distribution, and reproduction in any medium, provided the original author and source are credited. 
In Japan, aminophylline and theophylline agents were commercially available, but caffeine citrate was not. Therefore, to ascertain the safety, efficacy, dosage, and pharmacokinetics of caffeine citrate for use in treating apnea of prematurity in Japan, this trial was designed using the methods of the caffeine group in Study OPR-001 and the CAP trial(a randomized, double-blind, placebo-controlled trial) [13-16].

\section{Method}

This trial was carried out, in accordance with GCP, from November, 2011 to October, 2012 in the NICUs of 3 Japanese medical facilities as a non-blind, uncontrolled trial. The drug was administered to neonates satisfying all of the standards of eligibility for the clinical trial: a pause in breathing of greater than 20 seconds, or less than 20 seconds if accompanied by bradycardia (heart rate dropped below $100 \mathrm{bpm}$ ) or cyanosis (percutaneous blood oxygen saturation $\left(\mathrm{SpO}_{2}\right)$ was at or below $90 \%$ ).

Included in the study were neonates 24 hours after birth to children at the post-conceptional age of 28 to 33 weeks, neonates who experienced 6 or more confirmed apneic episodes in 24 hours, and neonates whose parents had agreed to allow participate in the clinical trial.

Neonates fitting any of the descriptions below were excluded from the clinical trial: (1) Those having hypoxic encepalopathy, or exhibiting its symptoms, on the grounds of possibly causing secondary apneic episodes; (2) BUN $>20 \mathrm{mg} / \mathrm{dL}$ and serum creatinine $>1.5 \mathrm{mg} / \mathrm{dL}$; (3) serum AST or ALT>triple the upper limit of the normal level; and (4) neonates receiving mechanical ventilation therapy, nasal CPAP or nasal DPAP; (5) those who had been administered a xanthine type drug in the 7 days prior to administration of the loading dose; (6) those who had been administered an $\mathrm{H} 2$ receptor antagonist (cimetidine, ranitidine, etc.) within 7 days prior to administration of the loading dose; (7) those being administered a central nervous activator; (8) those already participating in another clinical trial at the time their enrolment was considered. Neonates who were able to be taken off mechanical ventilation, nasal CPAP or nasal DPAP 12 hours or more prior to commencement were not excluded.

The neonates satisfying the selection criteria but not the exclusion criteria were administered an intravenous $20 \mathrm{mg} / \mathrm{kg}$ loading dose of caffeine citrate over 30 minutes. 24 hours after the administration of the loading dose, a once daily dose of $5 \mathrm{mg} / \mathrm{kg}$ was administered either intravenously over 10 minutes or orally and maintained for 9 days. If the doctor judged the initial maintenance dose to be ineffective, or the efficacy to be insufficient, the maintenance dose could be raised to 10 $\mathrm{mg} / \mathrm{kg} /$ day. Neonates were to be withdrawn from the study if mechanical ventilation, nasal CPAP or nasal DPAP was required or when the doctors judged them to be at risk of adverse events because the number of apnea episodes in a 24 -hour period was greater than $50 \%$ of baseline events and adverse effects were observed.

A primary outcome measure of efficacy, the number of Apneic episodes in the 24 hours before administration of the loading dose (the baseline) was recorded. Upon commencing administration, the number of apnea episodes was recorded from day 1 to 10 . The change in the percentage of neonates whose number of Apneic episodes had dropped to $50 \%$ or less of the baseline was evaluated.

The secondary outcome measures of efficacy were the following: 1) the change from the number of apnea episodes on each study day; 2) the change in the mean duration of Apneic episodes in a 24 hour period on each study day; 3 ) the change in the mean minimum $\mathrm{SpO}_{2}$ for the each 24 hour period on each study day; and 4) the change in the proportion of the number of apneic events having an $\mathrm{SpO}_{2}<85 \%$ in a 24 hour period, across the baseline and for the each 24 -hour period.

With regards to safety, the number (\%) of neonates who experienced at least one type of adverse event during caffeine administrating was determined. The serum concentration of caffeine and its metabolic products (theophylline, theobromine, and paraxanthine) was measured using high-performance liquid chromatography/tandem mass spectrometry (LC/MS/MS) at the following times: before (0), and 1 and $24 \mathrm{~h}$ after, administration of the loading dose, and 24 hours after administering the final maintenance dose. When it was possible, we measured the serum concentration of the caffeine on Days 5 and 8 after administration.

Analysis of the data was carried out using SAS for Windows (Version 8.2 or above). The proportion of neonates whose number of apneic episodes had dropped to $50 \%$ or lower (the primary outcome) was determined. However, in the cases in which the maintenance dose $(5 \mathrm{mg} /$ $\mathrm{kg} /$ day) was changed, or stopped, the Last Observation Carry Forward (LOCF) technique was used. For the secondary outcome measures, the value for the 24 hours preceding the administration of the loading dose was made the baseline; a 95\% Confidence interval calculation and a Wilcoxon signed-rank test were carried out for the fundamental statistic and the average value related to the difference between the observed value and that baseline.

The adverse effects were re-coded according to MedDRA/J (Ver. 15.1) and split up into the System Organ Class (SOC) and Preferred Term (PT) groups. Using the serum caffeine concentration measurement data from this trial and the U.S. clinical trial, a nonlinear mixed effects model (NONMEM Version 72.0) assessment based on a 1-component model including covariance was carried out, the individual case pharmacokinetics parameters were determined via Bayes estimator,

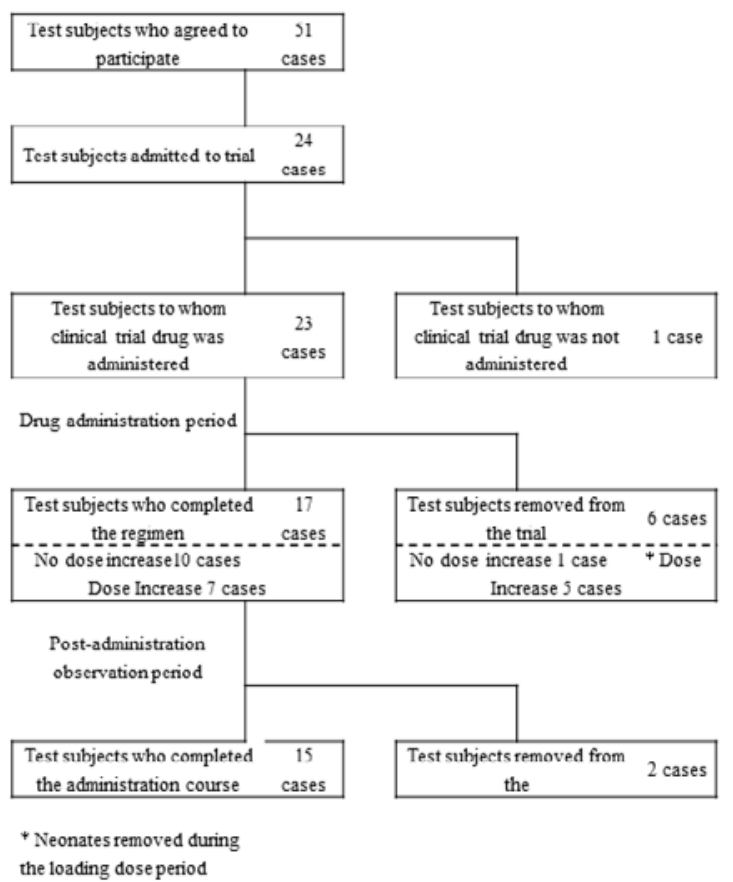

Figure 1: Makeup of the neonates in the study. 
Citation: Kondo M (2016) NPC-11 Phase III Trial Concerning Apnea of Prematurity in Japanese Neonates: A Study of Safety, Efficacy and Pharmacokinetics. Pharm Anal Acta 8: 458. doi:10.4172/2153-2435.1000458

Page 3 of 7

and the similarities between Japanese and U.S. subjects were compared.

\section{Results}

Of the 51 neonates for whom parental consent for this study had been obtained, 24 were included in the trial, and the caffeine citrate was administered to 23 . Of the 23 neonates, $15(65.2 \%)$ completed the trial. The trial was stopped for 6 neonates (26.1\%) during administration of the drug, and for 2 neonates (8.7\%) during the post-administration observation period (Figure 1). Of these 8 neonates, 5 were removed from the trial because of apparently insufficient efficacy (4 stopped during drug administration, 1 stopped during post-administration observation), 2 were removed because of mechanical ventilation ( 1 stopped during drug administration, 1 stopped during post-administration observation), and 1 was removed due to an adverse reaction that necessitated mechanical ventilation (stopped during administration).

With regard to dosing, after administration of a loading dose of 20 $\mathrm{mg} / \mathrm{kg}$ of caffeine citrate, the maintenance dose of $10 \mathrm{mg} / \mathrm{kg} /$ day was raised from the initial maintenance dose of $5 \mathrm{mg} / \mathrm{kg} /$ day in 12 of the

Table 1: Neonate patient background

\begin{tabular}{|c|c|c|c|c|}
\hline \multicolumn{2}{|l|}{ Item } & classification & & \\
\hline \multicolumn{3}{|c|}{ Number of test subjects suitable for analysis } & \multicolumn{2}{|c|}{$n=23$} \\
\hline \multirow{2}{*}{\multicolumn{2}{|c|}{ Sex }} & M & 9 & $(39.1 \%)$ \\
\hline & & $\mathrm{F}$ & 14 & $(60.9 \%)$ \\
\hline \multirow[t]{6}{*}{ Apgar Score } & \multirow[t]{3}{*}{ 1-minute } & Number of subjects & \multicolumn{2}{|l|}{23} \\
\hline & & Mean & \multicolumn{2}{|l|}{6.5} \\
\hline & & Standard deviation & \multicolumn{2}{|l|}{2.2} \\
\hline & \multirow[t]{3}{*}{ 5-minute } & Number of subjects & \multicolumn{2}{|l|}{23} \\
\hline & & Mean & \multicolumn{2}{|l|}{7.9} \\
\hline & & Standard deviation & \multicolumn{2}{|l|}{1.6} \\
\hline \multirow{3}{*}{\multicolumn{2}{|c|}{ Body length at birth $(\mathrm{cm})$}} & Number of subjects & \multicolumn{2}{|l|}{23} \\
\hline & & Mean & \multicolumn{2}{|c|}{39.66} \\
\hline & & Standard deviation & \multicolumn{2}{|c|}{3.65} \\
\hline \multirow{5}{*}{\multicolumn{2}{|c|}{ Birth weight (g) }} & Number of subjects & \multicolumn{2}{|l|}{23} \\
\hline & & Mean & \multicolumn{2}{|c|}{1512.7} \\
\hline & & Standard deviation & \multicolumn{2}{|c|}{377.7} \\
\hline & & Less than $1500 \mathrm{~g}$ & 13 & $(56.5 \%)$ \\
\hline & & 1500 to $2500 \mathrm{~g}$ & 10 & $(43.5 \%)$ \\
\hline \multirow{5}{*}{\multicolumn{2}{|c|}{ Gestational weeks at birth }} & Number of subjects & \multicolumn{2}{|l|}{23} \\
\hline & & Mean & \multicolumn{2}{|c|}{31.36} \\
\hline & & Standard deviation & \multicolumn{2}{|c|}{1.72} \\
\hline & & Under 30 weeks & 10 & $(43.5 \%)$ \\
\hline & & $\begin{array}{l}31 \text { weeks to less than } 34 \\
\text { weeks }\end{array}$ & 13 & $(56.5 \%)$ \\
\hline \multirow{5}{*}{\multicolumn{2}{|c|}{ Days after birth }} & Number of subjects & \multicolumn{2}{|l|}{23} \\
\hline & & Mean & \multicolumn{2}{|l|}{6.8} \\
\hline & & Standard deviation & \multicolumn{2}{|l|}{8.7} \\
\hline & & Under 4 days & 14 & $(60.9 \%)$ \\
\hline & & More than 5 days & 9 & $(39.1 \%)$ \\
\hline
\end{tabular}

23 neonates.

\section{Demographic characteristics}

Data on the characteristics of the study neonates are presented in Table 1. The 1 minute and 5 minute mean Apgar scores were 6.5 and 7.9 , respectively, and were approximately normal at birth. The mean birth weight was $1512.7 \mathrm{~g}$ with $56.5 \%$ of the neonates being below 1500 g. The mean gestational age was 31.4 weeks (range: 27.7 to 33.6 weeks) and the mean day after birth was 6.8 days (range: 1 to 36 days).

\section{Efficacy}

Primary outcome measure: The reduction rate of apneic events from the baseline in a 24 hour period were $60.9 \%$ on the first day and second days (Figure 2). From Day 3, the reduction rate of apneic events from the baseline fell into the stable range of 43.5 to $56.5 \%$ (Figure 2). In the 12 cases the maintenance dose was increased. In 6 of 12 cases, the caffeine increase was effective.

Secondary outcome measures: The mean number of apneic episodes in a 24-hour period dropped from 14.36 events of the baseline to 8.76 events on the first day, and transitioned to 7.70 or fewer events during the maintenance dose period. The study data confirmed that as the number of the caffeine administration days increased, the number of events decreased. The amount of the change in the mean apneic events compared to the baseline was -5.60 events on the first day of drug administration. During the maintenance dose period, this figure ranged from -6.32 to -11.28 . All of these results were statistically significant (Table 2).

Total duration of apneic events during each 24 hour period significantly decreased during the drug administration days, and with an increase in the number of drug administration days, the duration of apneic episodes decreased. The mean change from the 24 hour period before administration of the loading dose was -156.3 seconds on the first day, and during the period the maintenance dose was administered, the figure ranged from -153.8 to -274.6 seconds.

The mean change in the minimum $\mathrm{SpO}_{2}$ during apneic events over 24 hours was 2.3 to $10.6 \%$ higher during the study period (Table 2) while the mean change in the proportional number of apneic events with an $\mathrm{SpO}_{2}<85 \%$ during a 24 hour period showed a 8.94 to $10.69 \%$ decrease (Table 2).

When examining subgroups in terms of efficacy, differences between the sexes were disregarded. As birth weight increased, or as gestational age at birth lengthened or as day after birth became shorter, a trend towards somewhat higher efficacy became evident.

\section{Safety}

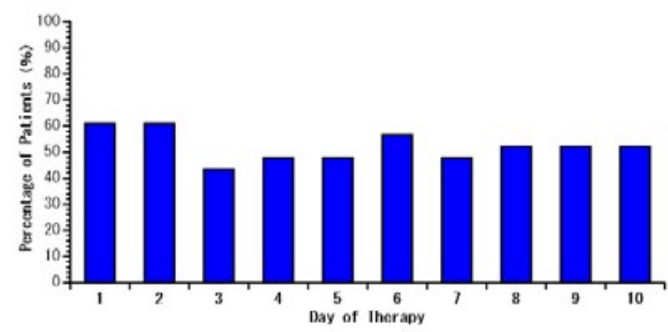

Figure 2: The percentage of infants with at least a $50 \%$ reduction in apnea events. 
Citation: Kondo M (2016) NPC-11 Phase III Trial Concerning Apnea of Prematurity in Japanese Neonates: A Study of Safety, Efficacy and Pharmacokinetics. Pharm Anal Acta 8: 458. doi:10.4172/2153-2435.1000458

Page 4 of 7

Table 2: Change in secondary outcome measures of efficacy.

\begin{tabular}{|c|c|c|c|c|c|c|c|c|c|c|c|c|}
\hline \multirow{2}{*}{\multicolumn{2}{|c|}{$\begin{array}{l}\text { Efficacy evaluation } \\
\text { measurement }\end{array}$}} & \multicolumn{11}{|c|}{ Day of dose administration } \\
\hline & & \multirow{2}{*}{$\begin{array}{l}\text { Pre-Admin } \\
23\end{array}$} & \multirow{2}{*}{\begin{tabular}{|l|} 
Day1 \\
23
\end{tabular}} & \multirow{2}{*}{$\begin{array}{l}\text { Day2 } \\
22\end{array}$} & \multirow{2}{*}{\begin{tabular}{|l|} 
Day3 \\
22 \\
\end{tabular}} & \multirow{2}{*}{\begin{tabular}{|l|} 
Day4 \\
21
\end{tabular}} & \multirow{2}{*}{\begin{tabular}{|l|} 
Day5 \\
19
\end{tabular}} & \multirow{2}{*}{\begin{tabular}{|l|} 
Day6 \\
18
\end{tabular}} & \multirow{2}{*}{$\begin{array}{l}\text { Day7 } \\
18\end{array}$} & \multirow{2}{*}{\begin{tabular}{|l|} 
Day8 \\
17
\end{tabular}} & \multirow{2}{*}{\begin{tabular}{|l|} 
Day9 \\
17 \\
\end{tabular}} & \multirow{2}{*}{$\begin{array}{l}\text { Day10 } \\
17\end{array}$} \\
\hline Change in & No. & & & & & & & & & & & \\
\hline during a 24 hour & Mean & 14.36 & 8.76 & 6.75 & 7.43 & 7.70 & 5.54 & 4.68 & 4.22 & 3.55 & 4.18 & 3.54 \\
\hline $\begin{array}{l}\text { period (events } / 24 \\
\text { hours) }\end{array}$ & SD & 7.39 & 8.10 & 5.87 & 6.76 & 11.58 & 6.23 & 5.72 & 3.61 & 3.24 & 4.53 & 4.01 \\
\hline & $95 \% \mathrm{Cl}$ & 11.17- & $5.26-$ & $4.15-$ & 4.43- & 2.43- & 2.54- & 1.84- & 2.43- & $1.89-$ & $1.85-$ & $1.48-$ \\
\hline & & 17.56 & 12.26 & 9.35 & 10.43 & 12.98 & 8.55 & 7.53 & 6.02 & 5.22 & 6.51 & 5.60 \\
\hline & Test $^{*}$ & - & 0.001 & $<0.001$ & $<0.001$ & 0.001 & $<0.001$ & $<0.001$ & $<0.001$ & $<0.001$ & $<0.001$ & $<0.001$ \\
\hline \multirow{6}{*}{$\begin{array}{l}\text { Duration of } \\
\text { apneic event } \\
\text { (seconds) }\end{array}$} & No. & 23 & 23 & 22 & 22 & 21 & 19 & 18 & 18 & 17 & 17 & 17 \\
\hline & Mean & 347.2 & 190.9 & 179.9 & 198.3 & 156.0 & 154.6 & 120.7 & 112.3 & 84.5 & 110.2 & 80.2 \\
\hline & SD & 198.9 & 184.6 & 184.0 & 221.2 & 195.3 & 199.5 & 171.1 & 109.3 & 87.7 & 140.7 & 111.7 \\
\hline & $95 \% \mathrm{Cl}$ & 261.2- & 111.0- & 98.3- & 100.2- & 67.1- & 58.4- & 35.7- & 58.0- & 39.4- & 37.9- & 22.7- \\
\hline & & 433.2 & 270.7 & 261.5 & 296.4 & 244.9 & 250.7 & 205.8 & 166.7 & 129.6 & 182.5 & 137.6 \\
\hline & test* & - & 0.001 & $<0.001$ & $<0.001$ & $<0.001$ & $<0.001$ & $<0.001$ & $<0.001$ & $<0.001$ & $<0.001$ & $<0.001$ \\
\hline \multirow{6}{*}{$\begin{array}{l}\text { Minimum } \mathrm{SpO}_{2} \\
\text { during apneic } \\
\text { event }(\%)\end{array}$} & No. & 23 & 21 & 20 & 19 & 19 & 16 & 13 & 16 & 15 & 14 & 15 \\
\hline & Mean & 72.7 & 75.0 & 76.7 & 75.6 & 78.6 & 78.8 & 81.4 & 80.5 & 78.7 & 81.4 & 79.3 \\
\hline & SD & 10.3 & 10.7 & 10.0 & 13.1 & 13.8 & 11.7 & 8.2 & 10.3 & 10.9 & 6.8 & 7.8 \\
\hline & $95 \% \mathrm{Cl}$ & 68.3- & 70.1- & 72.0- & 69.3- & 72.0- & 72.5- & 76.4- & 75.0- & 72.7- & 77.5- & 75.0- \\
\hline & & 77.2 & 79.9 & 81.3 & 81.9 & 85.3 & 85.0 & 86.3 & 86.0 & 84.7 & 85.3 & 83.7 \\
\hline & test $^{*}$ & - & 0.650 & 0.144 & 0.547 & 0.111 & 0.019 & 0.005 & 0.006 & 0.097 & $<0.001$ & 0.014 \\
\hline \multirow{6}{*}{$\begin{array}{l}\text { Proportion of } \\
\text { events having } \\
\mathrm{SpO}_{2} \text { less than } \\
85 \%(\%)\end{array}$} & No. & 23 & 21 & 20 & 19 & 19 & 16 & 13 & 16 & 15 & 14 & 15 \\
\hline & Mean & 35.00 & 44.74 & 42.35 & 44.90 & 41.94 & 40.87 & 33.25 & 43.96 & 37.17 & 32.76 & 38.07 \\
\hline & SD & 27.86 & 33.08 & 36.72 & 32.61 & 34.96 & 33.74 & 31.58 & 35.45 & 42.94 & 36.85 & 29.50 \\
\hline & $95 \% \mathrm{Cl}$ & 22.95- & 29.68- & 25.16- & 29.18- & 25.09- & 22.89- & 14.16- & 25.07- & 13.39- & 11.48- & 21.74- \\
\hline & & 47.05 & 59.79 & 59.53 & 60.62 & 58.79 & 58.85 & 52.33 & 62.85 & 60.94 & 54.03 & 54.41 \\
\hline & test $^{*}$ & - & 0.099 & 0.404 & 0.229 & 0.548 & 0.732 & 0.943 & 0.715 & 0.801 & 0.455 & 0.413 \\
\hline
\end{tabular}

The occurrence of adverse events was $78.3 \%$ (18/23 neonates), with the most common symptom being gastrointestinal disorder. The adverse events occurring most frequently were suckling sickness $(26.1 \%$, 6 neonates), vomiting, high blood pressure, and high body temperature (each 17.4\%, 4 neonates). Most adverse events were non-serious; there were 3 cases of mid-level adverse events (metabolic acidosis, rash, circulatory trouble). There were 2 examples ( 2 cases) of adverse event whose causal relationship was not discounted (1 cases of gastrointestinal bleeding and 1 cases of high blood pressure). No severe adverse effects were acknowledged.

\section{Pharmacokinetics}

The change in the serum caffeine concentration of the 23 neonate patients is shown in Figure 3. The mean concentration increased from 1.65 to $11.42 \mathrm{mg} / \mathrm{L}$ from before, to 1 hour after, administration of the loading dose. On Day 5 of administration (15 neonates) the mean concentration was $15.09 \mathrm{mg} / \mathrm{L}$, on Day 8 it was $18.82 \mathrm{mg} / \mathrm{L}$ (16 neonates) and at 24 hours after the final maintenance dose it was $18.55 \mathrm{mg} / \mathrm{L}$ (17 neonates). Serum concentrations of caffeine metabolic products (theophylline, theobromine, paraxanthine) were mostly below the fixed lower limits for neonates.
Figure 3: Change in serum caffeine concentration (Mean $\pm S D$ ).

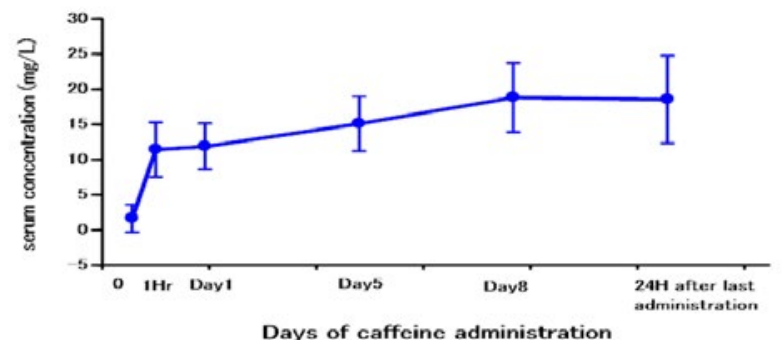

Next, the serum caffeine concentration data from our trial (23 neonates, 110 points) were combined with the serum caffeine concentration data from the U.S. trial (Study OPR-001), (58 neonates, 284 points), and a population pharmacokinetics analysis (NONMEM) was carried out. A fundamental model was constructed using the primary absorption process linear 1-compartment model. An exponent error model was applied to each pharmacokinetic parameter's variation between individuals, an absolute and mixed error model were applied to the 
residual error change in the individual, and the pharmacokinetic parameters examined. The neonates' background factors (race, sex, birth weight, gestational age at birth, day after birth, etc.), covariant with the fundamental model, were incorporated. The covariates showing a significant change in target function value ( $-2 \log$ likelihood of difference; level of significance: $<5 \%)$ were incorporated in the order of decreasing effect. The forward selection method was employed, and the full model was constructed. Because body weight, birth weight, and body weight at the commencement of drug administration were thought to have multicollinearity, in the cases where one or more of the factors were incorporated as covariates, other factors were not incorporated in the following step. Then, after constructing the full model, using backward elimination (back-step method), covariates were removed one at a time, and non-meaningful covariates (level of significance: $>1 \%$ ) were all removed. The resulting model was considered as the final version.

The standard parameters based on the final model (CL; Clearance, Vd; Volume of distribution, Ka; Absorption rate constant, Foral; Bioavailability) are shown below.

$\mathrm{CL}(\mathrm{L} / \mathrm{hr})=(0.0392 \times$ body weight $+0.0000865 \times$ birth age in days $)$ $\times \mathrm{e} 0.0472(\mathrm{CV}: 21.7 \%)$

$$
\begin{aligned}
& \mathrm{Vd}(\mathrm{L})=0.845 \times \text { body weight } \times \exp (0.050)(\mathrm{CV}: 22.5 \%) \\
& \mathrm{Ka}(/ \mathrm{hr})=0.991 \pm 0.355 \\
& \text { Foral }=0.895 \pm 0.0709
\end{aligned}
$$

Intra-individual variability: $5.25 \pm 1.20 \mathrm{mg} / \mathrm{L}$

In the final model constructed for this analysis, CL increased with an increase in body weight and day after birth, and Vd was proportional to bodyweight.

Because we compared racial differences in pharmacokinetics between Japanese and study OPR-001 subjects, race was examined as a covariate. However, as the covariate proved to be non-meaningful, the caffeine citrate was thought to have no difference in pharmacokinetics between Japanese and American neonates. The Bayesian inference value was determined for the individual test subject pharmacokinetic parameters (CL, Vd, Ka, Foral ) used in the final model of this analysis. Additionally, the $\mathrm{C}_{\text {max }}$ and $\mathrm{t} 1 / 2$ were calculated using the obtained pharmacokinetic parameters (Table 3 ).

Using the population pharmacokinetic parameters, the actual values obtained in our trial were plotted against a 100 -apnea-of-prematurity-case simulation (Figure 4). The change in the individual serum caffeine concentration of the neonates in our trial agreed well with the actual values. The estimability from the final model's Bayes inference parameters was good; a change of 5 to $30 \mathrm{mg} / \mathrm{L}$ was recorded in the serum concentration of the drug with a loading dose of $20 \mathrm{mg} / \mathrm{kg}$ and maintenance dose of $5 \mathrm{mg} / \mathrm{kg} / \mathrm{day}$, corresponding to the textbook estimates of the therapeutic range of the drug.

\section{Discussion}

This report is the first clinical trial (trial NPC-11-1) of Japanese neonates with apnea prematurity carried out observing GCP, which was conducted with the goal of examining the safety, efficacy, and pharmacokinetics of caffeine citrate. 24 Neonates were admitted to the trial and the drug was administered one or more times to 23 neonates ( 9 boys, 14 girls). The primary outcome measure and main secondary outcome measures (number of apneic events in a 24 hour period) were compared to the results of Study OPR-00113, a randomized, doubleblind, placebo-controlled trial period having the same trial period of 10 days. The primary outcome measure, the reduction rate of apneic events from the baseline in a 24 hour period was $60.9 \%$ on the first and second days. Throughout the maintenance dose period from Day 3 onward a stable change was demonstrated. A comparison with the results of Study OPR-001's double blind test period showed that the results were somewhat lower than for the OPR-001's drug group (45 neonates, $62.2 \%$ to $75.6 \%$ ), but higher than for the placebo group (37 neonates, $40.5 \%$ to $56.8 \%$ ). Additionally, the main secondary outcome measures showed a trend to lower values than seen in the Study OPR-001 caffeine group, but higher than in the placebo group.

For the efficacy sub-group examination (sex, birth weight, gestational week at birth, day after birth), sex was ignored. The resulting trend seemed to indicate somewhat higher efficacy as either birth weight increased, or as the number of gestational weeks at birth increased, or as the number of days after birth became decreased. In Study OPR-001, a clear correlation was found with the body weight background factor, whereas for the other background factors, either low, or no correlation was found.

In this clinical trial, death and other severe adverse events did not occur. The safety of this drug was confirmed by these results, which were similar to those of the previous trial (Study OPR-00113 and in an international joint multicenter collaborative trial (the CAP trial)). 1416 Adverse events (reactions) in which this trial could not exclude the drug as a causative factor, were mild gastrointestinal bleeding ( 1 neonate, twice) and mild hypertension (1 neonate, twice), but each of these were reported in the previous clinical research $[17,18]$ concerning drug administration for neonates. After commencement of drug administra-

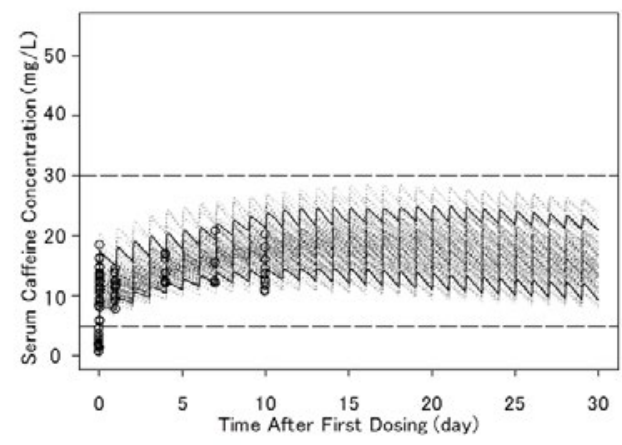

Figure 4: Simulation of population serum caffeine concentration pharmacokinetics positing a loading dose of the drug of $20 \mathrm{mg} / \mathrm{kg}$, followed 24 hours later by a maintenance dose of $5 \mathrm{mg} / \mathrm{kg} / \mathrm{day}$.

The dotted, zigzag lines indicate randomly simulated concentration changes in 100 neonates, the upper and lower bold lines are the $95 \%$ and $5 \%$ values, respectively, $\circ$ is the actual measured caffeine concentration, the bold zigzag lines are the therapeutic range (lower 2 lines) and the lower limit of the toxic range (upper 1 line).

Table 3: Estimated values (Mean \pm SD) of pharmacokinetic parameters for neonates included in the analysis.

\begin{tabular}{|c|c|c|c|c|c|}
\hline Trial & $\mathrm{N}$ & $\mathrm{C}_{\max }(\mathrm{mg} / \mathrm{L})$ & $\mathrm{t}_{1 / 2}(\mathrm{hr})$ & $\mathrm{CL}(\mathrm{L} / \mathrm{hr})$ & $\mathrm{V}_{\mathrm{d}}(\mathrm{L})$ \\
\hline Japan Phase 3 Clinical Trial & 23 & $12.41 \pm 2.26$ & $133.1 \pm 27.4$ & $0.0062 \pm 0.0018$ \\
\hline USA Study OPR-001 & 58 & $12.06 \pm 2.08$ & $137.0 \pm 32.1$ & $0.0054 \pm 0.0015$ \\
\hline
\end{tabular}

$\mathrm{C}_{\max }$ is the estimated value based on a single dose $20 \mathrm{mg} / \mathrm{kg}$ (administered IV: $20 \mathrm{mg} / \mathrm{kg} / 30$ minutes) 
tion, changes in clinical laboratory examination values, vital signs, and $\mathrm{SpO}_{2}$ stabilized and remained so during the maintenance dose period, and no effect on the respiratory system, cardiovascular system, or central nervous system was observed. The average serum caffeine concentration value quickly increased to the therapeutic range, and continued to be maintained stably within the therapeutic range for serum concentration. Conversely, the serum concentration of metabolic byproducts was, except in four neonates, below the fixed minimum value, suggesting that preterm neonates have a low ability to metabolize caffeine. The changes in serum caffeine concentration for both this clinical trial and Study OPR-001 were similar.

Caffeine is mainly metabolized in the liver by CYP1A2, CYP2E1, and CYP3A4. Because of this, drugs which either inhibit or induce CYP1A2 etc. could interact with the caffeine. However, because enzymatic metabolism of caffeine in the liver isn't fully developed in neonates, the effect due to drug interaction is thought to be limited. Next, in order to study the pharmacokinetics in the case of IV loading dose and IV or PO maintenance dose application, the serum caffeine concentration data from this trial (23 neonates, 110 points) and Study OPR-001 (58 neonates, 284 points) were combined, and a population pharmacokinetics analysis carried out. In the final model constructed for our analysis, $\mathrm{CL}$ increased with an increase in body weight and days after birth. Vd was a linear 1-component model proportional to body weight. Study OPR-001's final model for population pharmacokinetics analysis did not incorporate the effect of day after birth on CL, but some studies [19-22] examining the effect of caffeine in neonates have incorporated the effects of both body weight and day after birth. For this reason, this analysis was designed to incorporate the effect of body weight and day after birth on CL.

To compare any differences in the pharmacokinetics between Japanese and Americans subjects, this analysis used race as a covariate during the study. The result of the analysis proved that race was a nonmeaningful covariate on the grounds that no difference between these two groups was found in terms of pharmacokinetics. Caffeine pharmacokinetics are already a topic of investigation in apnea of prematurity among Caucasians [23] and Asians (Chinese, Malay).17 These studies demonstrated differences in the method (IV or PO) of administering caffeine (caffeine citrate or anhydrous caffeine), but revised caffeine pharmacokinetic parameters (serum caffeine concentration, $\mathrm{Vd}$ and t1/2) adjusted for body weight were almost identical for Caucasians and Asians. In preterm neonates, metabolic enzymes are not fully developed, and CYP1A2, CYP2E1, and CYP3A4, the principal metabolic enzymes for caffeine, genetic polymorphism frequency showed no clear differences between Japanese and Caucasians [24]. Furthermore, the change in caffeine concentrations among individual neonates in this study agreed well with the actual values.

In the final model constructed for our analysis, predictability based on the relationship between population-predicted values and individual-predicted values, time after administration, relationship between population-predicted values, and conditional weighted residuals was high, and from the bootstrap validation, robustness was also shown to be high, demonstrating the validity of our model for showing caffeine pharmacokinetics in preterm neonates.

\section{Conclusion}

Administration of caffeine citrate to treat apnea of prematurity in Japanese neonates demonstrated efficacy in reducing apneic episodes, no safety problems, and good tolerability. Additionally, no difference in efficacy, safety, or pharmacokinetics due to racial differences between Japanese and Americans was detected.

\section{Acknowledgement}

This study received partial financial support from National Institute of Biomedical Innovation, Health and Nutrition within the framework of the Program for Promotion of Orphan Drugs Development. Also this work is supported in part by Nobel Pharma Co. Ltd.

\section{References}

1. Stark AR (2008) Apnea: Manual of Neonatal Care (6th edn) Lippincott Williams and Wilkins, Philadelphia.

2. Thilo EH, Rosenberg AA (2009) Neonatal intensive care: Current Diagnosis and Treatment Pediatrics. (19th edn), McGraw-Hill Hay WW, New York.

3. (1985) American Academy of Pediatrics. Task Force on Prolonged Infantile Apnea. Prolonged infantile apnea: 1985. Pediatrics 76: 129-131.

4. Parmelee AH, Stern E, Harris MA (1972) Maturation of respiration in prematures and young infants. Neuropadiatrie 3: 294-304.

5. Alden ER, Mandelkorn T, Woodrum DE, Wennberg RP, Parks CR, et al (1972) Morbidity and mortality of infants weighing less than 1,000 grams in an intensive care nursery. Pediatrics 50: 40-49.

6. Barrington K, Finer N (1991) The natural history of the appearance of apnea of prematurity. Pediatr Res 29: 372-375.

7. Skouroliakou M, Bacopoulou F, Markantonis SL (2009) Caffeine versus theophylline for apnea of prematurity: a randomised controlled trial. J Paediatr Child Health 45: 587-592.

8. Poets CF (2010) Interventions for apnoea of prematurity: a personal view. Acta Paediatr 99: 172-177.

9. Schoen K, Yu T, Stockmann C, Spigarelli MG, Sherwin CM (2014) Use of methylxanthine therapies for the treatment and prevention of apnea of prematurity. Paediatr Drugs 16: 169-177.

10. Patel RM, Leong T, Carlton DP, Vyas-Read S (2013) Early caffeine therapy and clinical outcomes in extremely preterm infants. J Perinatol 33: 134-140.

11. Dobson NR, Patel RM, Smith PB, Kuehn DR, Clark J, et al. (2014) Trends in caffeine use and association between clinical outcomes and timing of therapy in very low birth weight infants. J Pediatr 164: 992-998.

12. Taha D, Kirkby S, Nawab U, Dysart KC, Genen L, et al. (2014) Early caffeine therapy for prevention of bronchopulmonary dysplasia in preterm infants. J Matern Fetal Neonatal Med 27: 1698-1702.

13. (1997) Clinical Evaluation of Sterile Caffeine Citrate Solution in the Treatment of Apnea of Prematurity.

14. Schmidt B, Roberts RS, Davis P, Doyle LW, Barrington KJ, et al. (2006) Caffeine therapy for apnea of prematurity. N Engl J Med 354: 2112-2121.

15. Schmidt B, Roberts RS, Davis P, Doyle LW, Barrington KJ, et al. (2007) Caffeine for Apnea of Prematurity. N Engl J Med 357: 1893-1902.

16. Schmidt B, Anderson PJ, Doyle LW, Dewey D, Grunau RE, et al. (2012) Survival without disability to age 5 years after neonatal caffeine therapy for apnea of prematurity. JAMA 307: 275-282.

17. Lee HS, Khoo YM, Chirino-Barcelo Y, Tan KL, Ong D (2002) Caffeine in apnoeic Asian neonates: a sparse data analysis. Br J Clin Pharmacol 54: 31-37.

18. Romagnoli C, De Carolis MP, Muzii U, Zecca E, Tortorolo G, et al. (1992) Effectiveness and side effects of two different doses of caffeine in preventing apnea in premature infants. Ther Drug Monit 14: 14-19.

19. Thomson AH, Kerr S, Wright S (1996) Population pharmacokinetics of caffeine in neonates and young infants. Ther Drug Monit 18: 245-253.

20. Lee TC, Charles B, Steer P, Flenady V, Shearman A (1997) Population pharmacokinetics of intravenous caffeine in neonates with apnea of prematurity. Clin Pharmacol Ther 61: 628-640. 
Citation: Kondo M (2016) NPC-11 Phase III Trial Concerning Apnea of Prematurity in Japanese Neonates: A Study of Safety, Efficacy and Pharmacokinetics. Pharm Anal Acta 8: 458. doi:10.4172/2153-2435.1000458

21. Falcão AC, Fernández de Gatta MM, Delgado Iribarnegaray MF, Santos Buelga D, García MJ, et al. (1997) Population pharmacokinetics of caffeine in premature neonates. Eur J Clin Pharmacol 52: 211-217.

22. Charles BG, Townsend SR, Steer PA, Flenady VJ, Gray PH, et al. (2008) Caffeine citrate treatment for extremely premature infants with apnea: population pharmacokinetics, absolute bioavailability, and implications for therapeutic drug monitoring. Ther Drug Monit 30: 709-716.

23. Aranda JV, Cook CE, Gorman W, Collinge JM, Loughnan PM, et al. (1979) Pharmacokinetic profile of caffeine in the premature newborn infant with apnea. J Pediatr 94: 663-668.

24. Wilner KD (2006) A trial to assess ethnicity and hint on how to design global/ Asian studies. Clin Eval 33: 219-232. 